\title{
Deinstitutionalizing Independence
}

\author{
Discourses of Disability and Housing in Accessible Computing
}

\author{
Kevin M. Storer \\ Department of Informatics, University of California, Irvine \\ storerk@uci.edu
}

\begin{abstract}
The meaning of "homes" is complicated for disabled people because of the historical link between (de)institutionalization, housing, and civil rights. But, it is unclear whether and how this history impacts Accessible Computing (AC) research in domestic spaces. We performed Critical Discourse Analysis on $101 \mathrm{AC}$ articles to explore how (de)institutionalization affects domestic AC research. We found (de)institutionalization motivates goals of "independence" for disabled people. Yet, discourses of housing reflected institutional logics which are in tension with "independence"-complicating how goals were set, housing was understood, and design was approached. We outline three discourses of housing in AC and identify parallels to those used to justify institutionalization in the USA. We reflect upon their consequences for AC research. We offer principles derived from the Independent Living Movement as frameworks for challenging institutional conceptions of housing, to open new avenues for more holistic and anti-ableist domestic AC research.
\end{abstract}

\section{CCS CONCEPTS}

-Human-centered computing $\rightarrow$ Accessibility; Accessibility theory, concepts and paradigms; - Social and professional topics $\rightarrow$ User characteristics; People with disabilities.

\section{KEYWORDS}

Institutionalization, Homes, Housing, Disability, Accessibility, Critical Discourse Analysis

\section{ACM Reference Format:}

Kevin M. Storer and Stacy M. Branham. 2021. Deinstitutionalizing Independence: Discourses of Disability and Housing in Accessible Computing. In The 23rd International ACM SIGACCESS Conference on Computers and Accessibility (ASSETS '21), October 18-22, 2021, Virtual Event, USA. ACM, New York, NY, USA, 14 pages. https://doi.org/10.1145/3441852.3471213

\section{INTRODUCTION}

Despite computing's workplace-oriented origins, many technologies are designed to be deployed in homes [84]. While this shift in context, from professional to private environments, has enabled opportunities for computing to enhance domestic life, it has also necessitated changes to research approaches employed to examine technology use. Introducing digital technologies in domestic

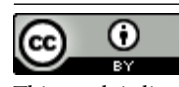

This work is licensed under a Creative Commons Attribution International 4.0 License.

ASSETS '21, October 18-22, 2021, Virtual Event, USA

(C) 2021 Copyright held by the owner/author(s).

ACM ISBN 978-1-4503-8306-6/21/10.

https://doi.org/10.1145/3441852.3471213

\author{
Stacy M. Branham \\ Department of Informatics, University of California, Irvine \\ sbranham@uci.edu
}

settings can have unintended consequences for significant aspects of domestic life, like intimate relationships [106], domestic labor [4, 89], and familial roles [68]. But, because homes are familiar to most people, these social factors may seem unremarkable-and remain unexamined-if researchers are not reflective and critical in their analyses [9]. Though well-established in computing research concerning people-not-specified-as-disabled, few studies in Accessible Computing (AC) examine domestic technologies for disabled people ${ }^{1}$ through social lenses [19, 30, 104, 105]. However, orienting toward social aspects and employing critical approaches may be especially important for domestic AC researchers because of historical connections between disability and housing, which add nuance to researching domestic AC.

Carceral institutions, sometimes euphemistically referred to as "homes," 2 have been a primary residence for disabled people throughout modern history. Adopted in the United States of America (USA) during the 1850 s, institutionalization was the default "method of handling" disabled people, labelled "deviant, defective, or delinquent," for over a century [76]. There are numerous accounts of unspeakable abuses in institutional settings [32, 50]. But, the institutional system remained largely unchallenged until the 1950s, when growing awareness of abuses and medical advances prompted calls for deinstitutionalization, or the transition of disabled people to community-based settings [28]. In the wake of this transition, disabled activists and their allies continued to push for further deinstitutionalization and full civil rights under the banner of the Independent Living (IL) Movement [41]. The IL Movement's goals were, and are, broader than deinstitutionalization. But, its namesake evidences the pivotal role of (de)institutionalization ${ }^{3}$ and housing in disabled people's fight for justice.

Because social factors impact technology design in domestic spaces, and housing is linked to disability rights, the successful design of domestic AC systems likely requires understanding the social significance of housing for disabled people as contextualized by (de)institutionalization. To understand how historical connections between disability and housing impact domestic AC design research, we performed Critical Discourse Analysis on 101 articles which address digital technologies, disability, and housing, employing (de)institutionalization as an analytical lens.

\footnotetext{
${ }^{1}$ We use identity-first language (e.g. "disabled people") to reflect a Social Model of Disability, which posits disability is caused by discriminatory policies, infrastructures, and attitudes, not by a supposed limitation of one's body [78].

${ }^{2}$ Because of the dual meaning of "home," we use "institutional" and "community-based" to refer to the level of carcerality of a specific environment. "Housing" (noun) and "domestic" (adjective) refer to a more general concept of living environments.

${ }^{3}(\mathrm{De})$ institutionalization refers to the collective history of institutionalization and deinstitutionalization. Institutionalization and deinstitutionalization (without parentheses) refer to periods within this history, in which the number of institutionalized disabled people increased and decreased, respectively.
} 
We found the history of (de)institutionalization guides contemporary domestic AC research. In particular, supporting communitybased living for disabled people, often referred to as "independence," was a common design goal and motivational narrative in the reviewed works. Yet, the history of (de)institutionalization, which contextualizes these goals, was not explicitly discussed. Instead, institutionalization was primarily discussed in relation to contemporary types of institutions, like nursing homes and long-term care facilities-and surrounding discourses described contemporary institutions in the same terms used to justify institutionalization in the USA. Because community-based living was understood primarily in contrast to institutional living, institutional discourses were also present in discussions of community-based settings and placed boundaries around how "independence" was understood. Consequently, much AC design research conducted in pursuit of "independence" evidenced institutional commitments in tension with the principles advocated by the IL Movement.

Here, we share a brief history of (de)institutionalization in the USA. We outline discourses observed within the reviewed literature, drawing parallels to dominant societal logics which justified institutionalization in the nineteenth-century USA. We discuss how examining disabled people's domestic lives primarily through the lens of a community-based/institutional dichotomy may 1) introduce institutional logics into our discussions of independence, in ways that are counterproductive to goals of supporting communitybased living for disabled people, and 2) leave many important aspects of community-based domestic life underexplored in $\mathrm{AC}$ research. We reflect upon challenges in contesting these narratives while conducting research that responds to problems of immediate importance to disabled people, in societies where the practice of institutionalization is a continued reality. We offer three principles established by the IL Movement's activism which challenge institutional understandings of disability and housing, to promote future domestic AC research in which goals of "independence" set by AC researchers are aligned with goals of "independence" advanced by the IL Movement.

\section{BACKGROUND AND RELATED WORK}

\section{1 (De)Institutionalization in the USA}

The practice of institutionalizing disabled people was invented in Western Europe in the 1750s and adopted in English North America a century later [76]. In the colonial USA, disabled people typically lived in residential settings, where family and local community members provided any necessary care. At this time, colonists had a predominantly agrarian economy, and more people in the community-regardless of their (dis)abilities-was beneficial for performing agricultural labor. Additionally, in tight-knit rural communities, caring for community members was perceived as a responsibility of being a community, not a responsibility caused by any one individual's (dis)abilities. So, most colonists in the USA did not see a major need for state intervention in caring for disabled family and community members. This perception changed when three major shifts in economic, scientific, and moralistic cultural attitudes converged between the late-eighteenth and mid-nineteenth centuries.

As the USA's economy shifted during the First American Industrial Revolution, families were drawn away from rural communities which contributed to the care of disabled family members, to urban areas where extrafamilial social connections were looser [76]. Simultaneously, where distinguishing between disabled and nondisabled people had been largely irrelevant in agricultural labor, industrialization "re-created the category of worker" [29], such that "disability," as a descriptor of people, was invented to indicate whether one could operate factory machinery. This change in economic structure labeled disabled people both as defective workers and burdensome on their families and the economy.

During this same period, acceptance of two threads in societal thinking promoted institutionalization as a solution to the growing "problem" of disabled people [76]. Firstly, scientific advances of the European Enlightenment gained popularity in North America and cast doubt on previous assumptions that disability was attributable to divine influences. Instead, it was reasoned that disability had natural origins which could be scientifically explained. Secondly, the USA was experiencing the Second Great Awakening-a Protestant Christian revival emphasizing believers' moral duties to improve the lives of those perceived as disadvantaged, like disabled people. This convergence of scientific and religious thought suggested 1) disability could be scientifically "cured" and 2) attempts to do so were morally righteous.

The unity in scientific and moralistic logics driving institutionalization in the USA is evident in the use of "asylum" to describe carceral institutions. But, accounts of unspeakable abuses inflicted upon disabled people in institutional settings rebut notions that institutions served to provide clinical services or that their implementation was ethical [32, 50]. Horrific portrayals of asylums in popular culture serve as well-known examples of such abuses, which make the institutionalization of cognitively and intellectually disabled people especially visible. But, physically disabled people were also frequently institutionalized in facilities with similarly troublesome histories, despite being euphemistically referred to as "schools" [76].

Institutionalizing disabled people remained a normalized aspect of life in the USA until the 1950s and 60s, when economic, scientific, and moralistic attitudes shifted again. Following the Great Depression, state-run institutions were lacking in financial resources, raising questions about the merits of public investment in them. Simultaneously, the advent of psychiatric medications in 1954 offered the possibility to provide some clinical services in community-based settings-at a lower cost to the state-prompting healthcare professionals to advocate for deinstitutionalization [28]. These economic concerns and scientific advances led to increased scrutiny into the activities of institutions. Awareness of their abuse grew throughout the 1960s-against the backdrop of the Civil Rights movement in the USA, which was already prompting conversations about societal treatment of marginalized groups.

The successes of Civil Rights leaders prompted critical reflection by disabled activists, who realized their rights "would come only as [they] fought for them" [1]. So, disabled people and their allies united around of the goal of securing disabled people's right to 
"participate fully in all areas. .. of mainstream community living on a par with nondisabled peers" [7] under the banner of the IL Movement. Disabled leaders within the IL Movement organized remarkably bold protests, including the longest occupation of a federal building to date [1]. Their labor and tenacity led to significant legislative reforms in the USA. Notable examples include 1) the Lake v. Cameron ruling in 1966 which mandated hospitals treat people in the "least restrictive setting" possible [29], 2) the passage of the Rehabilitation Act in 1973 which prohibited discrimination on the basis of disability in programs receiving federal resources [41], 3) the passage of the Americans with Disabilities Act (ADA) in 1990 , which broadly mandated accessibility in public spaces and workplaces [3], and 4) the 1999 Olmstead Decision, which ruled that requiring disabled people to live in institutional settings is an unlawful act of discriminatory segregation, and community-based supports must be provided where appropriate and desired [79].

The IL Movement remains a significant political force today [1], in part, because it is not clear the deinstitutionalization of disabled people was fully accomplished. Particularly visible examples of contemporary institutions in the USA are nursing homes and care facilities, in which many disabled people, often older adults, still reside. More subtle examples can be seen in the USA's prison system, in which as many as $40 \%$ of incarcerated people are disabled-twice the reported rate of disability in the nonincarcerated population [62]. This transition from living in clinical institutional settings to criminal institutional settings, and only temporarily in communitybased settings, has been termed "transinstitutionalization" [91].

Additionally, for brevity, the history provided is partial, focusing on a broad construal of "disability," the USA, and experiences of White $^{4}$, English colonists. But, institutionalization was, and is, enacted differently across geographies and on the basis of disability, race, and gender. Today, a disproportionate number of disabled people institutionalized in carceral settings are Black, men, and cognitively disabled [95]. Similarly, we focus on two types of housing. But, disabled people are also more likely than nondisabled people to be unhoused [96], adding complexity to discussions of housing justice and disability. Here, it is not feasible to unpack particularities of (de)institutionalization across geographies, disabilities, races, and genders, nor to frame this discussion inclusive of incarceration and lack of housing as intersections of disability and housing external to a community-based/institutional dichotomy. But, these topics merit future research and, though not discussed further, evidence need for additional critical inquiry in domestic AC.

\subsection{Social and Critical Perspectives of Domestic Technologies}

In Human-Computer Interaction (HCI) research addressing peoplenot-specified-as-disabled, domestic spaces are understood as a particularly nuanced context for technology design, which can be explored from a multiplicity of perspectives. A recent review by

\footnotetext{
${ }^{4}$ We capitalize "White" in accordance with an opinion from the Center for the Study of Social Policy that "[t]o not name 'White' as a race is, in fact, an anti-Black act which frames Whiteness as both neutral and the standard" [75]. Others prefer lower-case "white" to contrast with the recognition that capitalizing "Black reflects a shared sense of identity and community... in the absence of the identifiable ethnicities slavery stole from those it subjugated" [60]. We see merit in both these arguments and do not intend to advocate for either convention.
}

Desjardins et al. [31] found HCI has as many as seven different genres of research on domestic technologies, each with unique goals and metrics of success. Some approach domestic spaces primarily as a testing site for novel smart-home technologies [24, 55]. Others examine them as a site of interpersonal connection and intimacy $[18,51,52]$. Still others approach domestic spaces as a context with embedded sociocultural values, impacting technology design and use $[9,10]$.

Although perspectives of domestic spaces in HCI are diverse, they are not necessarily discretely bounded. Many empirical works indicate connections between disparate social considerations of domestic spaces. For instance, technologies which negatively impact commonly held values, like privacy, can be tolerated if they increase familial connection [52]. Technologies for managing domestic labor, like shared calendars, can impact interpersonal relationships by prompting negotiations about sharing content [106]. Technologies designed to increase interpersonal connection, like teleconferencing, can introduce domestic labor, like tidying the space in a webcam's view [4]. Divisions of labor involved in maintaining digital technologies are affected by larger societal values, like gender norms [89]. Domestic technologies can even affect perceptions of social roles within a family, for example, by altering conceptions of how to be a "good parent" [68]. Because of these complex social factors impacting domestic technology design, Bell et al. [9] recommend adopting a deeply reflective and critical stance when working in domestic spaces, to develop holistic understandings domestic technology design.

The finesse required in domestic technology design research is well established in HCI literature people-not-specified-as-disabled. But, social and critical approaches to domestic AC research remain rare. So, it is unclear how social considerations of disability in domestic spaces exist alongside, intersect with, or extend beyond those identified in prior studies of people-not-specified-as-disabled. Our work probes this domain through a critical investigation of one social aspect of housing which is connected to disability-the history of (de)institutionalization in the USA.

\subsection{Social and Critical Perspectives of Accessibility}

Since Mankoff et al.'s [67] introduction of Disability Studies (DS) to AC in 2010, social and critical perspectives of disability and accessibility are the subject of a growing body of research in AC. A key focus of this work is the use of critical, anti-ableist lenses provided by DS to challenge AC's assumptions about disability, to highlight novel opportunities for research and promote ethical research for and with disabled people. Mankoff et al. [67] challenged AC's use of the Medical Model of disability, which posits disability is caused by an individual's bodily impairments and can be "fixed," in this case, by AC systems. In its place, the Social Model of disability, which posits disability is caused by external structural factors and larger systems of oppression, has become a popular perspective. Accordingly, a growing body of work addresses social factors impacting AC design, like how access is constructed through social interactions $[19,104,107,112,115]$, the social acceptability of AC systems [86, 87, 97-99], and how digital technologies mediate social interactions between disabled and nondisabled [20, 23, 43, 105]. But, 
the success of adopting the Social Model in AC has also inspired explorations into other models of disability in AC, like Critical Realist [40] and Political/Relational [12] models, each with their own strengths. More broadly, the success of employing the critical approaches of DS in AC has inspired works adopting critical perspectives on topics like dementia [61], aging [110], mental health [88], independence [12], and empathy [13].

These efforts suggest AC may have interests in the social nuances of domestic environments. But, few works have examined social factors impacting accessible domestic technology design. Those which have suggest domestic AC system design involves social considerations similar, and in addition, to those previously identified in studies of people-not-specified-as-disabled. Dawe found nondisabled family members of cognitively disabled people should be understood as stakeholders in AC system design, because they may be responsible for device maintenance [30]. Branham and Kane found accessibility of domestic spaces for blind inhabitants depends upon the skills and empathy of sighted housemates, who, for instance, prepare spaces to be accessible for blind housemates by consistently orienting objects in agreed upon ways [19]. Storer and Branham found examining blind people's social roles within families, specifically as parents, highlights new opportunities for $\mathrm{AC}$ systems to support accessibility in the activities required by those roles [99]. Similarly, Storer et al. found when adopting devices to increase accessibility in domestic spaces, blind people may weigh their access against household concerns of adopting technologies, like impacts on interpersonal relationships, privacy, and children's safety [105].

We build on these bodies of work, by conducting a critical examination of the history of (de)institutionalization as it shapes discourses of housing and research trajectories in $\mathrm{AC}$ and as it intersects with other social considerations impacting AC design in nuanced domestic spaces.

\section{METHODS}

\subsection{Critical Discourse Analysis}

To examine the effects of (de)institutionalization on discourses of housing in AC, we performed Critical Discourse Analysis (CDA) on a body of literature from the Association for Computing Machinery (ACM). CDA has an extensive history in humanistic disciplines, by many accounts, originating in the work of Foucault [39]. Recent works in computing have used CDA as an approach to Critical Literature Reviews (CLRs) to examine how specific topics are discussed across a research community [53, 102]. But, CDA remains less established in computing than similar methods, like Thematic Analysis [22] and Systematic Literature Reviews (SLRs) [54]. So, while a comprehensive history of CDA is not possible here, the differences between these approaches merit explication.

CDA is an interdisciplinary "research programme," [113] encompassing a variety of approaches, perspectives, and methods. At its core, CDA is an abductive approach to "de-mystifying ideologies and power through the. . investigation of semiotic data" [113]. The use of abduction in logic is attributed to Charles Sanders Peirce, who described abduction as a form of reasoning in which "The surprising fact, $C$, is observed. But if $A$ were true, $C$ would be a matter of course. Hence, there is reason to suspect that $A$ is true"
[81]. As such, CDA flows between theory-driven, deductive reasoning and data-driven, inductive reasoning throughout analysis. For this reason, CDA differs from Thematic Analyses [22] which typically identify patterns inductively, without $a$ prioi frameworks to guide inquiry. These analytical differences also make the goals of CLRs distinct from those of SLRs [51]. SLRs often aim to categorize works in a domain to map the landscape of a research area (for example, see [31] or [35]). By contrast, the abductive approach of CLRs using CDA is designed to examine implicit understandings guiding how a topic is discussed. So, although our methods for collecting texts are systematic, as in SLRs [54], our goal in analyzing these articles is not to provide an overview of domestic AC research. Rather, we explore how housing is discussed in these works, and examine whether and how (de)institutionalization explains observed patterns in these discussions.

\subsection{Collecting the Corpus}

The first author collected 1,037 articles, by searching the ACM Digital Library (DL) for works published by the ACM over the decade from January 2010 to December 2019, containing the keywords \{home*; hous*; domestic $\left.{ }^{*}\right\}$ and classified using the 2012 ACM Computing Classification System (CCS) terms \{Accessibility; Assistive technologies; People with disabilities; Seniors\}. We conducted our final search on March $18^{\text {th }}, 2020$. These criteria were developed collaboratively by the first and second author, with the following considerations:

1) We analyzed only ACM articles, for pragmatic reasons. Many disciplines relate, somehow, to housing and AC. So, it was not feasible to examine all related fields. For reference, a Google Scholar query analogous to our final query yielded over one-million results.

2) We analyzed only works published in the decade between January 2010 and December 2019, to attend to changes impacting discourses of AC and domestic technologies. Research in AC dates to at least the 1960s (for example, [103]). But, perceptions of disability have changed significantly over time. Patterns of domestic technology use has also changed, as more people adopt digital technologies in their homes [84]. Analyzing all works across time would likely unearth discourses which do not represent current interests.

3) We used the search terms $\left\{\right.$ home* ${ }^{*}$ hous*; domestic ${ }^{*}$ \}, based on Desjardins et al.'s review of HCI literature on domestic design outside the context of AC, which additionally included \{everyday\}. We found, in the context of AC, \{everyday\} was not closely related to domesticity, typically meaning "mundane." We considered borrowing keywords from outside resources, like Schlesinger et al. [92]. But, surveying thesauri for synonyms of "home" and "housing" did not yield viable results.

4) We targeted AC articles by collecting works using the 2012 CCS terms \{Accessibility; Assistive technologies; People with disabilities; Seniors\}, which is exhaustive of accessibility CCS terms. Some collected literature was published prior to the shift in CCS concepts in 2012. In the 1998 CCS A Assistive Technologies for Persons with Disabilities\} was the only accessibility classifier and is no longer indexed on the DL. 
Table 1: Analyzed venues, results collected, and total filtered by 1) level of peer-review, 2) use of housing keywords, and 3) topic fit. In total, the 576 works from these venues were reduced to a final corpus of 101.

\begin{tabular}{|c|c|c|c|c|c|}
\hline \multirow[b]{2}{*}{ Publication Venue } & \multirow[b]{2}{*}{ Results } & \multicolumn{3}{|c|}{ Filtering Criteria } & \multirow[b]{2}{*}{ Total } \\
\hline & & Review & Keywords & Topic & \\
\hline $\begin{array}{l}\text { SIGACCESS Conference on Computers and Accessibility } \\
\text { (ASSETS) }\end{array}$ & 197 & 37 & 49 & 73 & 38 \\
\hline $\begin{array}{l}\text { SIGCHI Conference on Human Factors in Computing } \\
\text { Systems (CHI) }\end{array}$ & 91 & 22 & 23 & 29 & 17 \\
\hline $\begin{array}{l}\text { Pervasive Technologies Related to Assistive } \\
\text { Environments Conference (PETRA) }\end{array}$ & 50 & 19 & 6 & 8 & 17 \\
\hline Transactions on Accessible Computing (TACCESS) & 65 & 1 & 17 & 31 & 16 \\
\hline $\begin{array}{l}\text { Proceedings of the ACM on Human-Computer Interaction, } \\
\text { Issue CSCW/ACM Conference on Computer Supported } \\
\text { Cooperative Work and Social Computing (CSCW) }\end{array}$ & 20 & 4 & 1 & 11 & 4 \\
\hline Transactions on Computer-Human Interaction (TOCHI) & 9 & 0 & 2 & 4 & 3 \\
\hline European Conference on Cognitive Ergonomics (ECCE) & 44 & 15 & 2 & 24 & 3 \\
\hline International Web for All Conference (W4A) & 74 & 17 & 41 & 14 & 2 \\
\hline $\begin{array}{l}\text { Proceedings of the ACM on Interactive, Mobile, Wearable } \\
\text { and Ubiquitous Technologies/ International Conference } \\
\text { on Ubiquitous Computing (IMWUT) }\end{array}$ & 24 & 14 & 4 & 5 & 1 \\
\hline Transactions on Applied Perception (TAP) & 2 & 0 & 0 & 2 & 0 \\
\hline Total & 576 & 129 & 145 & 201 & 101 \\
\hline
\end{tabular}

But, at the time of our search, we found works originally using this 1998 classifier were indexed under the 2012 terms used. We considered constructing a list of Accessibility keywords, as for housing. But, disability language varies. Selecting terms which we judged as representative would bias our collection toward works whose language use matches ours. Conversely, general terms, like "access," returned many unrelated results.

\subsection{Filtering the Corpus}

To reduce our dataset to a size feasible to analyze, we developed four criteria for filtering the 1,037 works collected:

1) Publication Venue. To tailor our findings to our audience, we analyzed the five conferences and five journals in which conversations around housing and disability are most frequent, based on the number of articles returned in our search. For communities which have shifted from conferences to journals, we included conference proceedings affiliated with journals meeting our criteria.

2) Level of Peer-Review. To ensure all reviewed articles were fully peer-reviewed, the first author manually removed articles with less than three pages of content, or published in lightly-reviewed formats, like extended abstracts.

3) Use of our Housing Keywords. The first author searched for each occurrence of $\left\{\right.$ home $^{*}$; hous*; domestic $\left.{ }^{*}\right\}$ and removed works which used these words only in ways not pertaining to housing (for example, "Gross Domestic Product," "Homepage").

4) Relatedness to Topic. The first author read the introduction and abstract of each work remaining after the above filtering to determine relatedness to our topic. To be included, a paper's abstract or introduction needed to mention some topic related to disability, aging, or chronic illness, and to domestic spaces and/or some activity typical of domestic settings (eating, showering, etc.). When a topical connection was loose, we tended toward inclusion.

Table 1 shows analyzed venues and counts of results returned and filtered in each round. Journal publications extending works published in conference proceedings were analyzed as unique contributions, as multiple works show these discourses have persisted over time. Notably, neither article collected from ACM Transactions on Applied Perception was related to our topic, leaving nine venues in our final analysis. After filtering, our corpus contained 101 articles. The first author read each in full to examine discourses of housing discussed below.

\section{FINDINGS}

We found the history of (de)institutionalization structures discourses of housing in contemporary AC research. References to institutional and community-based living were common in our corpus. Setting "independence" as a primary goal of AC system design was also common. But, the history of (de)institutionalization was not explicitly addressed in these works. Instead, institutionalization was primarily discussed in relation to contemporary institutions, like nursing homes. Discourses surrounding contemporary institutions normalized their existence using similar economic, scientific, and moralistic frameworks as those which first justified institutionalizing disabled people in the USA (described in Section 2.1). Importantly, because community-based living and its associated value of "independence" were positioned as opposite to institutional living, discussions of community-based living and independence were often subject to these same logics. That is, we found economic, 
scientific, and moralistic discourses of community-based living and independence which were complementary to, and consistent with, the understanding that contemporary institutions are normal and justifiable for similar reasons as institutions in the nineteenthcentury USA. So, collectively, these works evidenced a commitment to setting goals of community-based living and independence. But, they approached these goals from distinctly institutional perspectives, which complicated and undermined their attainment.

\subsection{Economic Discourses of Housing}

Economic logics in the First American Industrial Revolution, which framed disabled people as burdens on their families and the economy, were a catalyst for institutionalization in the USA. Within our corpus, we found discourses surrounding contemporary forms of institutionalization often adopted similar economic and resourceoriented analytical lenses. These economic discourses were particularly frequent in discussions of disabled people transitioning to and from institutional living.

Discourses surrounding deinstitutionalizing disabled people often emphasized the resources expended on transitions to community-based settings. For example, Kosch et al. noted "[p]eople with cognitive impairments currently leverage extensive human resources during their transitions from assisted living to independent living" [59]. Some works identified educational labor involved in community-based living, like Sitbon et al., who noted, "a focus in recent years on life skills training and rehabilitation for people with intellectual and learning disabilities. This has come from a move from institutions into homes" [100]. Others pointed to the presence of "facilities [that] have emerged to foster and train independent living skills" [58] and "institution[s] to help people with disabilities to. . .integrate with the society by organizing various trainings" [64]. In these examples, community-based living was portrayed as being made possible through the labors of others and society.

In contrast, discussions of institutionalizing disabled people often framed transitions to institutional settings as an effortless response to circumstances. For example, van Dijk et al. motivated their research by noting " $[\mathrm{t}]$ here are many reasons people may be forced to leave their homes. . . and start a new lifestyle in a nursing home" [33]. Likewise, Vacher et al. described institutionalization as a "de facto course of action" in certain situations [108]. Others indicated circumstances may lead to "having to send people to care homes" [69], or to disabled people "having to receive institutionalized care" [83]. Notably, this perception that institutionalization is a direct outcome of circumstances was also shared by some research participants. One interviewee of Birnholtz and Jones-Rounds, indicated an imagined system might be acceptable "if it meant the difference between being able to stay wherever it was I was living or having to move into someplace that's more structured and regulated" [15], alluding to institutional facilities. The role of others and society in institutionalizing disabled people was notably absent from these discussions. Instead, responsibility for institutionalization was placed on situational factors, not requiring the intervention-or effort-of any individual.

The dichotomy between the above economic discourses of deinstitutionalization and institutionalization portrayed an institutional system in which becoming independent was resource-intensive and required deliberate effort from others, while becoming institutionalized was effortless and a result of circumstance. Importantly, this perception of independence-as-effort was pervasive in our corpus, even outside the context of transitions between institutional and community-based settings. For instance, in the design of domestic AC systems, authors often indicated goals of "enabling" independence $[15,21,36,58,59,83]$, reflecting the conception independence is created through others' labor. At a deeper level, ideas of independence-as-effort were also reflected in perceptions of disabled people living independently. Many reviewed works suggested disabled people in community-based settings were, in some way, a resource burden on others $[5,19,65,70,73,82,83,111]$. Skorupska et al. suggested older adults in community-based settings were a burden on the economy and society, more broadly, motivating their crowdworking platform by citing a "shortage of adequate researchinformed activities and programs allowing them to contribute to the society" [101]. In this sense, disabled people becoming and being independent were both portrayed as resource intensive activities.

Within a framework where disabled people's community-based living and independence are the result of the ongoing labor of others, institutionalization is inevitable. That is, since independence is created through resources provided by others and society, given enough time, these resources will be depleted, and independence will be rescinded. Accordingly, we found many works in our corpus suggested independence was an inherently temporary state of being. For example, Vacher et al. noted disabled people "want to stay in their residence for as long as possible" [108]. McGeeLennon et al. suggested designed systems might help "people with disabilities. . .stay active and independent for longer in their own homes" [69]. Other works indicated "seniors wish to remain independent" [15] and disabled people made "some adaptations [to their homes] in order to stay independent" [109], where "remaining" and "staying" allude to the threat to independence caused by time. In this way, because independence was resource-intensive and ultimately unsustainable, institutionalization is portrayed as a force of nature.

Because institutionalization was perceived as inevitable, efforts aimed at constructing independence for disabled people may be viewed only as delaying institutionalization, rather than preventing it. So, when goals of community-based living and independence were set, disabled people's independence was typically discussed as something aimed at rather than attained. For example, independence was often described as something to be "supported" $[17,27,85,94,100,115]$, to be "increased" $[14,16,49,111]$, to be "promoted" [34], or to be "improved" [33] by design efforts. Where community-based living was framed as resulting from others' labors, the inevitability of institutionalization suggested efforts aimed at independence will eventually fail, rendering goals of independence fundamentally out of reach for researchers. Importantly, these boundaries further emphasized the resources involved in independence, by calling into question whether efforts made in pursuit of independence will-or can-ultimately achieve their goals.

As a collective, we found economic logics of institutionalization were mirrored in discourses of community-based living and independence. Where institutionalization was portrayed as reflexive and automatic, independence was portrayed as deliberate and difficult. Where institutionalization was the result of forces beyond 
the control of other individuals and society, independence was portrayed as possible only because of others and society. Put more simply, disabled people's institutionalization was nature's fault, and their independence was society's achievement. Notably, positioning institutionalization and independence within this framework largely problematized disabled people's community-based living and independence. Metaphorically speaking, within these works, independence was akin to swimming upstream-a laborious, active resistance against natural forces, which can only be sustained temporarily. Put more directly, disabled people's independence was a problem which, when eventually too burdensome for others, will be solved by institutionalization.

\subsection{Scientific Discourses of Institutionalization}

Scientific advances of the Enlightenment justified institutionalization in the USA, by suggesting disabilities may be clinically treated or "cured." Within our corpus, we found discourses surrounding contemporary forms of institutionalization often adopted scientific and clinical views of the function of institutions in society.

Specifically, many works within our corpus suggested institutionalization is, in some way, beneficial for disabled people's health and clinical wellbeing. In fact, discussions of institutionalizationas-clinically-beneficial were intertwined with the portrayal of institutionalization as a result of circumstance, discussed above. That is, institutionalization was inevitable because of clinical healthcare becoming increasingly complex over time, due to aging or accidents. For instance, one of the "many reasons people may be forced to leave their homes," described by van Dijk et al. [33], is "due to a degrading physical or mental condition." Likewise, institutionalization was described as the "de facto course of action," by Vacher et al. [108], "after a fall [because] falls have serious [health] consequences.”

Conversely and accordingly, we found many cases where disabled people's community-based living and independence were portrayed as being in tension with their health and safety. For instance, in observing disabled people in the kitchen, professional caregivers were noted to "make crucial tradeoffs between safety concerns and independence" [59]. Viswanathan et al. noted, because of these tensions, "older adults with cognitive impairments are excluded from powered wheelchair use because of safety concerns. This leads to. . .higher dependence" [111]. Likewise, Holbøet al. [47] described "the risk of relying on one's own abilities" when walking alone. Madjaroff and Mentis found participants in their study also perceived these tensions, such that the "autonomy of the carerecipient would often be compromised due to the need for safety that was expected by the caregiver" [66]. Importantly, portraying institutionalization as clinically beneficial and community-based living and independence as threatening to physical well-being, casts both institutional and community-based living within a clinical framework. That is, since institutionalization is necessary in cases of complex clinical healthcare needs, sustaining independence is a clinical problem, in which safety and adequate healthcare are the dividing line between institutional and community-based living. In emphasizing clinical aspects of institutional and community-based living, we found discourses of domestic life-even in communitybased settings-were often medicalized, in areas which would likely be viewed as nonclinical outside the context of disability.
For instance, domestic labor is routine in the domestic spaces of many people. But, within the context of AC, domestic labor tasks were typically discussed as part of "Activities of Daily Living" or ADLs. For example, Belley et al. [11] contributed insights toward smart-home recognition of older adults' performance of ADLs, like making tea and cooking toast, bacon, and pancakes. Similarly, Mulvenna et al. [73] designed the COGKNOW system for people with dementia, to "support daily activities" like controlling domestic infrastructures, preparing and eating meals, and using household appliances. Importantly, the phrase ADL was not simply a way to describe domestic labor. Rather, describing domestic labor as ADLs alluded to the use of domestic labor performance as a clinical measure, which determines whether disabled people will be institutionalized. For instance, Caroux et al. motivated their work, by stating ADLs "are abilities defining the functional status of an individual. Verifying what ADLs are performed by an older adult is a decisive factor to determine... .whether aging in place is desirable" [26]. Peters et al. noted, "[p]roblems related to this [cognitive] functioning appear in a human's daily routines where the successful execution of Activities of Daily Living (ADLs) is an integral part of an autonomous and self-determined life" [82]. Indeed, Bhattacharjee et al. motivated their work by referring to a prior study which found "needing help with one of more ADLs is the most cited reason for moving to assisted or institutionalized living" [14]. So, although examining domestic labor is important in understanding domestic life, in the reviewed works, domestic labor primarily manifested as a clinical measure of ability-more specifically-the ability to remain independent and in community-based living.

Familial relationships are also a particularly important and nuanced aspect of domestic life. But, within the context of AC, familial relationships were also frequently discussed in clinical terms. Specifically, within our corpus, familial relationships were typically defined by caregiving/care-receiving interactions. For example, Madjaroff and Mentis conducted a study with the purpose of understanding "the narratives of people living with a mild cognitive impairment as well as their partners that live with them and provide care" [66]. In a separate study, Mentis et al. noted "older adults with MCI often cope with...the help of caregivers, including partners [and] children" [72]. Peters et al. noted "informal care-givers such as family members worry about the well-being of care recipients" [82]. Likewise, Alves et al. designed "a mobile application that allows communication and information sharing between informal caregivers, namely family and friends" [2]. Several works designed systems specifically to support family members in their role as healthcare providers. For example, Parnandi et al. designed a speech therapy tool "potentially allowing for a higher intensity of practice than is typically possible with parent-directed home practice" [80]. Elor et al. shared a system "for upper limb rehabilitation, which can be set up inside or outside the therapy office by a caregiver or family member" [37]. For Vacher et al., this emphasis on familial caregiving is directly related to disabled people's independence and living environment in that, due to the aging population, "it is likely that families will have to provide more support than in the past century given the reduced availability of specialized institutions" [109]. In this way, family members are framed as extensions of the institutional system, providing healthcare, rather than supportive 
social connection. Caregiving could be viewed as a central component of most familial connections-cooking for one's spouse or children, for example. But, here, the clinical emphasis of caregiving downplayed the inherent intimacy of familial connections, by portraying interactions as medically-oriented and unidirectionally beneficial. That is, family members are shown to care for, but not necessarily care about or with disabled people. Likewise, disabled people are shown to receive care from, but not necessarily provide care to, their family members.

Similarly, leisure and play are important aspects of domestic life, in that private domestic spaces serve as non-professional settings where occupants can freely engage in nonutilitarian activities. But, within the context of $\mathrm{AC}$, leisure activities were most commonly discussed as vehicles for delivering clinical care, or for deemphasizing the clinical aspects of therapy. For example, Korn and Tietz outlined recommendations for "gamifying rehabilitation" in order to improve adherence to clinical regimens "at home without regular observation by a therapist" [57]. Sitbon et al. drew on previous insights into "[i]nteractive, game-like Virtual Environments" when designing immersive videos to train disabled people in common life skills [100]. Parnandi et al. suggested "game-like features and animations would increase the patient's interest" in therapy tools for apraxia of speech [80]. Gerling et al. designed wheelchair-based games with the goals of "improving [older adults'] cognitive, physical, and emotional well-being" [42]. Similarly, Hornof et al. presented a media player designed to motivate a young girl with Rhett Syndrome to begin "interacting with her world as was needed to learn cause and effect" [48]. While leisure activities were frequently discussed as an aspect of domestic life, it is unclear leisure was the intent of these designs promising playfulness. Rather, these leisure activities served as metaphorical "spoonfuls of sugar to help the medicine go down," since their playful aspects were intended to deemphasize, or hide, their purpose as vehicles for delivering clinical care to disabled users.

As a collective, we found discourses which portrayed institutionalization as scientifically and clinically beneficial for disabled people were reflected in conceptions that community-based living and independence are clinically challenging, or even dangerous. Consequently, domestic life-in both institutional and communitybased settings-is best understood within clinical frameworks. As such, in our corpus, many nonclinical aspects of domestic life, including domestic labor, familial relationships, and leisure, were discussed primarily in relation to their clinical utility. Indeed, receiving appropriate clinical care within the local community is an important aspect of domestic life for disabled and nondisabled people, and domestic labor, familial relationships and leisure may have clinical benefits for people regardless of their (dis)abilities. However, the clinical aspects of domestic labor, familial relationships, and leisure are but one of many qualities which define communitybased domestic life. Here, the predominance of clinical perspectives left other significant aspects of domestic life, like distribution of domestic labor, intimate connection, and playfulness, largely unexamined.

\subsection{Moralistic Discourses of Institutionalization}

The religious fervor of the Second Great Awakening in the USA justified institutionalization, in that believers felt institutionalizing disabled people was a moral and ethical act of helping disadvantaged members of society. Within the reviewed works, we found discussions of ongoing forms of institutionalization frequently adopted similar moralistic languages, and presented institutionalization as benevolent and helpful for disabled people.

In particular, when contemporary institutions were discussed, they were most often not identified as institutional settings. Rather, these institutions were euphemistically described as "nursing homes" [2, 33, 42, 56, 72, 74, 90, 108], "sheltered living" [58, 59], "care facilities" $[8,14,15,74,111]$, or "care centers" $[2,6,45,65]$. Notably, these phrases are common in vernacular English. But, it is important to recognize that by sidestepping discussions of institutions as institutions, these optimistic euphemisms both deemphasize institutions' carceral qualities and emphasize their supposed benevolent qualities - nursing, shelter, and care. The benevolence of institutions was similarly emphasized in discussions of the activities happening within institutional settings. Professional staff working within institutions were frequently described as "caretakers," "caregivers," or "assistants" [2, 33, 58, 90], suggesting caring for or assisting disabled people is a primary responsibility of their job.

At the same time, the specific duties described as being involved in "caring for" disabled people in institutional settings often had distinctly carceral qualities. For example, one role of the "caretakers" described by Scheffler et al. [90] was to retrieve "patients [who] walk away from the nursing home," and return them back to the institution. Similarly, van Dijk et al. indicated "care professionals" in institutions may gatekeep social interactions, in that "[m]ost of the social contacts in rehabilitation centers and nursing homes are based on scheduled visits" [33]. Yet, these activities were typically understood as being clinically justified, as discussed above, and therefore carried out in the care of disabled people. In fact, at a higher level, many works indicated helping disabled people was a primary societal function of institutions. For example, sheltered living facilities "offer people with cognitive impairments assistance with learning," [59], nursing homes provide "help to get up" [56], and halfway houses "help people with disabilities to rehabilitate" [64]. Together, these discourses framed institutions as benevolent and staffed by people who care for disabled people, working within an institutional system which serves to help. Even when carceral aspects of institutions were identified, they were secondary to institutions' benevolent qualities, understood as modes of caregiving, and portrayed as ways institutional systems help disabled people.

This understanding of institutions-as-helpful promoted conceptions that institutional modes of care are ethical frameworks for guiding the design of domestic AC systems. For instance, Becker et al. motivated their exploration into activity recognition in a smart home environment by noting "[i]t is critical to provide a means to help the individual [with disabilities] in their home as they would be helped should they be in a care facility" [8]. Others sought design inspiration from institutional settings and institutional caregivers. For instance, Bhattacharjee et al. provided design recommendations 
for a robot-assisted feeding system based on insights from a study "in an assisted-living community with five potential care recipients and five caregivers. . . fifteen domain experts including occupational therapists and feeding specialists" [14]. Peters et al. based their design of an assistive toothbrushing system on interviews with caregivers, because "[c]aregivers are experts in prompting since they provide professional nursing care in the task of brushing teeth as part of their daily routine" [82]. Likewise, Kosch et al. provided insights for the design of a cooking assistance system, based on a comparative study of "participants in a sheltered living facility that were supported by either caretaker assistance or in-situ assistance" [58]. Professional caregivers may be an important source of domain-specific knowledge. But, by guiding design using insights from institutional caregivers, these works could equally be seen as suggesting institutional models of care are desirable standards of care which design should emulate, or by which AC systems' efficacy should be measured.

One consequence of framing institutional models of care as desirable models to emulate in design was that many AC systems for community-based settings in our corpus were designed to achieve carceral goals. In particular, many systems in our corpus were designed to surveil disabled people. For example, Becker et al. designed an ambient assistive living environment in which various sets of sensors were "deployed to monitor human activity" [8]. Caroux et al. shared an approach to "verifying the activities of daily living of older adults at their home. . supported by a lightweight sensor infrastructure" [26]. Meliones et al. presented a domestic "adaptive intelligent video surveillance and motion detection system employing a network of IP cameras for patient monitoring" [71]. Holbøet al. indicated "[r]emote monitoring, such as electronic tracking, may be perceived as a means of enhancing personal safety" in community-based settings [47]. Anderson et al. suggested their MANA gait monitoring system "can be used at home as it is a convenient and invisible wearable system" and "battery life makes long term monitoring using MANA a strong possibility" [5]. Ferdous et al. pointed to "recent advances in RFID Technology [like those for] monitoring elderly people at home" [38] to motivate their techniques for managing data generated by such systems. Systems for surveilling disabled people in community-based settings were prevalent enough that Consel et al. even identified "monitoring of activities of daily living" as one of the "main domains of assisted living" [27]. Additionally, several works explored privacy concerns with such systems. Vacher et al. indicated "there is a balance between the benefit of such monitoring (sensors of all kinds) and the intrusion into privacy" [109]. Similarly, McNeill et al. expressed a concern "that some developers assume, sometimes without asking, that while older adults desire to live independent, there is a need for some kind of health supervision in order [to] protect them from harm" [70]. It is important to recognize these tensions. However, it is unsurprising that privacy may be intruded by these designs, as lack of privacy through surveillance is a mode of institutional "care" emulated by these systems.

Taken together, we found discourses surrounding contemporary institutions portrayed institutionalization as part of a benevolent system which helps disabled people. This conception was reflected in the framing of institutional approaches to care as desirable models for design to emulate in community-based settings. Clinical caregivers and institutional practices were important sources of design insights. Consequently, many domestic AC systems replicated the carceral logics applied to "caring for" disabled people in institutional settings. Importantly, here, design goals of independence were not necessarily undermined by carceral design solutions. Rather, surveillance itself was understood as a mode of creating independence for disabled people.

\section{DISCUSSION}

\subsection{Institutional Discourses of Housing}

At a high level, we found evidence the history of (de)institutionalization shapes recent domestic AC research approaches and trajectories. The historical connection of housing to disability rights manifested most commonly in authors setting goals of "independence" within the reviewed works. But, the ongoing presence of contemporary institutions, and the normalization of them, placed limitations on what could be said about community-based living and independence within these texts. Specifically, we found discourses surrounding contemporary institutions often adopted economic, scientific, and moralistic perspectives which paralleled those used to justify institutionalizing disabled people in the nineteenth-century USA. These logics portrayed institutionalization as an effortless result of circumstance, clinically beneficial, and helpful to disabled people. Correspondingly, we found discourses of community-based living and independence portrayed as a temporary and laboriously constructed state, clinically dangerous, and best supported by institutional models of care.

Importantly, the institutional discourses of housing in these works not only shape what can be said, they also impact how domestic AC design research can be executed. In his canonical The Reflective Practitioner, Donald Schön describes the work of design as a cycle of problem setting and problem solving, in which:

When we set the problem, we select what we will treat as the 'things' of the situation, we set the boundaries of our attention to it, and we impose upon it a coherence which allows us to say what is wrong and in what directions the situation needs to be changed [93].

In Schön's terms, discourses evidence commitments to what is treated as the "things" of the situation, influencing problem setting. Here, the history of (de)institutionalization and the normalization of contemporary institutions present a situation in which the problem set is: disabled people in community-based settings are 1) burdensome, 2) clinically endangered, and 3) would be helped by being institutionalized. By setting the problem in these terms, the boundaries of attention paid to it and the directions in which the situation should change are also defined.

Consider, for example, Elor et al.'s system "for upper limb rehabilitation, which can be set up inside or outside the therapy office by a caregiver or family member" [37]. The ongoing history of (de)institutionalization suggests "what is wrong" is disabled people in community-based settings are clinically endangered. So, a lack of clinical care available outside the therapy office is an appropriate problem to set. In setting the problem this way, the boundaries of attention to it become limited to clinical concerns. The fungibility of "caregiver" and "family member" in this sentence suggests the 
attention paid to family members in this scenario is bounded to their clinical utility. By setting the problem as a clinical problem and limiting the boundaries of design attention to clinical concerns, building a system to provide clinical services outside of clinical settings which employs the aid of pseudo-clinician family members becomes a viable mode of problem solving. But, the viability of solving the problem with clinical design solutions follows the setting of the problem in clinical terms-and the problem is set in clinical terms because of scientific conceptions of disability and housing rooted in the ongoing history of (de)institutionalization. Similar patterns can be found in economic and moralistic discourses of housing, where crowdworking platforms solve the problem of a "shortage of. . programs allowing [disabled people] to contribute to the society" [101], and surveillance systems solve the problem of "help[ing] the individual [with disabilities] in their home as they would be helped should they be in a care facility" [8]. In this way, the discourses of housing explicated in this work are not simply words on a page-but dominant logics of society, and of the AC community specifically, which implicitly guide how the "things" of design situations are selected and, consequently, how problems are set and solved.

Additionally, we believe how we write about these issues not only has practical implications for AC design research, but also ethical implications for how our collective work contributes to societal understandings that institutionalization is normal and justifiable. A key claim of much CDA is that discourses have a dialectical relationship with societal power structures [114]. That is, discourses are shaped by political relations and shape political relations. In accepting the political relations of the institutional system without critique or caveat, we not only implicitly orient our problems to these frameworks, we reinforce the normalcy of the institutional system. This may be an especially critical issue for AC researchers, as our discussions are documented in archival texts, which are peerreviewed and granted positions of authority. Many of our readers may be nonacademic, turning to us as experts on this topic, while lacking historical context available to seasoned scholars. For fellow academics, it is important novel research engages in conversation with existing work. So, how discourses of housing are constructed in current research directly impacts how future work is approached and produced. Together, failing to address the problematic history of (de)institutionalization in these works perpetuates institutional logics, by omission, and promotes additional research which further perpetuates these logics, by demanding research is relevant to current domains of inquiry in $\mathrm{AC}$, which have been built on institutional logics. The cycle repeats.

At the same time, in critiquing these discourses and explicating their practical and ethical implications for AC research, our goal is not to discredit the reviewed works-some of which are our own. Nor do we intend to suggest AC researchers are individually responsible for dismantling nor upholding the institutional system through their research and design praxis. The dominant economic, scientific, and moralistic ideologies discussed reflect those held, more broadly, by many societies in which AC researchers are situated. So, the presence of institutional discourses in AC research should not necessarily be interpreted as reflecting AC researchers' individual intentions or thinking. Rather, institutional discourses, and the complexity they add to discussions of community-based living, highlight inherent tensions in challenging institutional systems while working within larger societal structures which shape the problems that might be addressed by technology design. The reviewed works, even where critiqued, accurately depict societal realities and speak to vital issues affecting many disabled people. For instance, many technologies considered here to be "institutional" fill gaps in the availability of community-based services whose public funding, in the USA, varies widely due to regional politics and can be prohibitively expensive to pay out of pocket [44]. Currently, this gap is most often filled by women whose labor is unpaid [25], who may also benefit from the support provided by institutional domestic AC systems. So, our aim in this work is not to argue that tackling institutional design problems is wholly without merit, nor that the discourses critiqued here should, or even could, be completely abandoned in AC research.

However, we believe the centrality of "independence" to the works in our corpus is evidence of communal goals of achieving permanent community-based living for disabled people. Institutional discourses of housing in AC may shape the setting and solving of design problems in ways that are fundamentally antithetical to this goal. This dissonance suggests a need to balance a pragmatic desire to address problems of immediate importance to disabled people with the acknowledgement-and challenging-of social injustices produced by the historical and ongoing practice of institutionalization, which place boundaries around technology's ability to solve those problems. In this way, our exploration of institutional logics embedded in discourses of housing in $\mathrm{AC}$ is a call for both 1) alternative perspectives on housing which expose novel modes of problem setting, and 2) more nuanced discussions of disability and housing which engage housing's connection to (de)institutionalization as simultaneously accurate and ableist, prescient and problematic, normalized and contestable.

\subsection{Deinstitutionalizing Independence}

Hofmann et al. argued "that naming ableism is necessary for its revision. Accepting this enables learning and growth to move past debating whether discrete acts are ableist, to revising them" [46]. In this spirit, identifying the ableism inherent to institutional discourses of housing is not an accusation levied against the AC community or any critiqued works. Instead, in conducting this CDA we aim to name ableism where it exists and invite conversation about how we may collectively revise these acts.

Discussions of anti-ableist research praxis are not new to AC. But, challenging ableism in our discourses of housing may require different approaches than previous challenges to ableism in AC. Many critical theories of disability, particularly those employed in AC, focus on where disability exists or is produced-in the body or in socio-material infrastructures [67], in both body and sociomaterial infrastructures [40], or in interactions between bodies and socio-material infrastructures [12], to name only a few perspectives. Shifting perceptions of where disability exists or is produced is important for rethinking disabled bodies. But, alone, these theories may not be effective in displacing ableist conceptions of housing.

As a first step toward revising our shared discourses of housingand deinstitutionalizing our perspectives of independence-we share three principles, adopted from the advocacy of the IL Movement and the legislative victories it achieved, which we believe 
can be productively applied toward adopting anti-ableist perspectives on housing in $\mathrm{AC}$ and inform future work in deinstitutional domestic design research.

1) Upholding Independence as a Right. In the reviewed works, we found when institutionalization was portrayed as effortless and reflexive, independence was described as temporary and laborious. The IL Movement argues independence is an innate civil right, not a constructed state. While civil rights are not unalienable without limitation (consider the well-known example of shouting "Fire!" in a crowded theater), understanding independence as a right positions independence as the default state, prioritizes its normalcy over that of institutions, and frames independence as natural, not constructed. From this perspective, institutionalization can be seen as an unnatural infringement upon disabled people's rights, rather than a reflexive response to "burdensome" independent disabled people.

2) Domestic Research on Par with Nondisabled Peers. When institutionalization was framed as clinically beneficial, independence was portrayed as clinically dangerous, and most aspects of domestic life were understood in terms of their clinical utility. The IL Movement is not simply a fight to receive clinical care in domestic settings. Rather, it advocates disabled people's right to "participate fully in all areas. . . of mainstream community living on a par with nondisabled peers" [7]. In this language, issues other than clinical care are known to be an important part of full participation in mainstream community living, by HCI researchers $[9,10,52,68,89,106]$. But, the academic attention paid to these issues is not on a par with nondisabled peers. This framing highlights opportunities for AC research which aims for community-based living to be equally fulfilling for disabled people as for their nondisabled peers-not just possible in light of the continued threat of institutionalization.

3) Least Restrictive Design Approaches. When institutionalization was framed as helpful, design approaches replicating institutional models of care in community-based settings were understood as viable methods of supporting independence. On one hand, replicating institutional care in community-based settings can be viewed as a means of providing the community-based supports required by the 1999 Olmstead Decision [79]. On the other, introducing surveillance technologies into community-based settings 1) risks promoting transinstitutionalization [91] by shaping community-based housing into pseudo-institutional spaces, and 2) makes disabled people's domestic spaces inherently more restrictive than they would otherwise be-potentially undermining the principle of "least restrictive setting" of the Lake v. Cameron ruling [28]. We suggest, even if communitybased surveillance is less restrictive than institutional surveillance, the Lake v. Cameron ruling suggests designing supports which impose as little restriction as possible may be the more important goal.

In the reviewed works, goals of "independence" set by AC researchers were often dissonant with goals of "independence" set by the IL Movement. These principles give the latter priority. Prior discussions in AC of disabled people in caregiving roles [104], home-décor as a vehicle for self-expression [63], and housing as a site of nostalgia [15] exemplify some deinstitutional perspectives on housing, though not discussed directly in relation to (de)institutionalization. There is room for future research which explicitly attends to these principles and probes their impacts on design. We hope they inspire more holistic explorations of disabled people's domestic lives and future work which can further deinstitutionalize our discussions of disability, housing, and independence.

\section{LIMITATIONS}

A limitation of this work is its analysis of only ACM AC articles, such that we did not examine discourses of disability and housing in related domains. Some neighboring disciplines have clinical foci, which may partly explain the presence of the clinical discourses we identified in AC. Bibliometric analysis of citation patterns between $\mathrm{AC}$ and adjacent domains might be beneficial for further analyzing factors influencing AC research trajectories and represents an opportunity for future work.

Additionally, we began this exploration prior to widespread recognition of COVID-19. However, COVID-19-particularly stayat-home orders-has fundamentally changed global perspectives on housing. It is unknown how domestic life will be reconfigured in the near future and how the discourses explored here will intersect with new understandings of housing. But, we believe COVID-19 emphasizes, rather than undermines, the contribution of this work. Domestic spaces now commonly serve as a setting for both personal and professional activities, and disabled people have been disproportionately affected by COVID-19, particularly those in institutional settings [77]. This work reflects upon current research trajectories to guide future efforts. Since domestic life is being renegotiated and COVID-19 reemphasized the dangers of institutionalization, setting new trajectories is a timely goal. But, future readers of this work will have perspectives of housing, institutions, and disability shaped by COVID-19 in ways that are presently unknowable.

\section{CONCLUSION}

We performed CDA on $101 \mathrm{AC}$ articles to understand how the history of (de)institutionalization shapes discourses of housing in AC. We identified three ways in which discourses surrounding contemporary forms of institutionalization placed boundaries upon how goals of independence were set, how life in community-based settings was understood, and how designing for community-based settings was approached. We reflected on the consequences of these discourses in shaping AC research trajectories and identified three principles advocated by the IL Movement which might challenge dominant discourses of housing and open avenues for future domestic AC research which adopts deinstitutional values.

\section{ACKNOWLEDGMENTS}

This work is supported by NSF Award \#1850251.

\section{REFERENCES}

[1] About Independent Living: 2012. https://ncil.org/about/aboutil/. Accessed: 202009-13.

[2] Alves, S., Brito, F., Cordeiro, A., Carriço, L. and Guerreiro, T. 2019. Designing Personalized Therapy Tools for People with Dementia. Proceedings of the 16th 
Web For All 2019 Personalization - Personalizing the Web (New York, NY, USA May 2019), 1-10

[3] Americans with Disabilities Act of 1990,AS AMENDED with ADA Amendments Act of 2008: https://www.ada.gov/pubs/adastatute08.htm\#12101. Accessed: 201905-28.

[4] Ames, M.G., Go, J., Kaye, J. "Jofish" and Spasojevic, M. 2010. Making Love in the Network Closet: The Benefits and Work of Family Videochat. Proceedings of the 2010 ACM Conference on Computer Supported Cooperative Work (New York, NY, USA, 2010), 145-154

[5] Anderson, B., Zhu, S., Yang, K., Wang, J., Anderson, H., Tay, C.X., Tan, V.Y.F. and Wang, Y. 2018. MANA: Designing and Validating a User-Centered Mobility Analysis System. Proceedings of the 20th International ACM SIGACCESS Conference on Computers and Accessibility (New York, NY, USA, Oct. 2018), 321-332.

[6] Aruanno, B., Garzotto, F., Torelli, E. and Vona, F. 2018. HoloLearn: Wearable Mixed Reality for People with Neurodevelopmental Disorders (NDD). Proceedings of the 20th International ACM SIGACCESS Conference on Computers and Accessibility (New York, NY, USA, Oct. 2018), 40-51.

[7] Barnes, C. 2014. Independent living, politics and implications. (2014)

[8] Becker, E., Arora, R., Phan, S., Vinjumur, J.K. and Makedon, F. 2010. Extending event-driven experiments for human activity for an assistive environment Proceedings of the 3rd International Conference on PErvasive Technologies Related to Assistive Environments (New York, NY, USA, Jun. 2010), 1-8.

[9] Bell, G., Blythe, M. and Sengers, P. 2005. Making by Making Strange: Defamiliarization and the Design of Domestic Technologies. ACM Trans. Comput.-Hum Interact. 12, 2 (Jun. 2005), 149-173. DOI:https://doi.org/10.1145/1067860.1067862.

[10] Bell, G. and Dourish, P. 2007. Back to the shed: gendered visions of technology and domesticity. Personal and Ubiquitous Computing. 11, 5 (2007), 373-381.

[11] Belley, C., Gaboury, S., Bouchard, B. and Bouzouane, A. 2013. Activity recognition in smart homes based on electrical devices identification. Proceedings of the 6th International Conference on PErvasive Technologies Related to Assistive Environments (New York, NY, USA, May 2013), 1-8.

[12] Bennett, C.L., Brady, E. and Branham, S.M. 2018. Interdependence as a Frame for Assistive Technology Research and Design. Proceedings of the 20th International ACM SIGACCESS Conference on Computers and Accessibility (2018), 161-173.

[13] Bennett, C.L. and Rosner, D.K. 2019. The Promise of Empathy: Design, Disability, and Knowing the" Other". Proceedings of the 2019 CHI Conference on Human Factors in Computing Systems (2019), 1-13.

[14] Bhattacharjee, T., Cabrera, M.E., Caspi, A., Cakmak, M. and Srinivasa, S.S. 2019 A Community-Centered Design Framework for Robot-Assisted Feeding Systems. The 21st International ACM SIGACCESS Conference on Computers and Accessibility (New York, NY, USA, Oct. 2019), 482-494.

[15] Birnholtz, J. and Jones-Rounds, M. 2010. Independence and interaction: understanding seniors' privacy and awareness needs for aging in place. Proceedings of the SIGCHI Conference on Human Factors in Computing Systems (New York, NY, USA, Apr. 2010), 143-152.

[16] Bonani, M., Oliveira, R., Correia, F., Rodrigues, A., Guerreiro, T. and Paiva, A. 2018. What My Eyes Can't See, A Robot Can Show Me: Exploring the Collaboration Between Blind People and Robots. Proceedings of the 20th International ACM SIGACCESS Conference on Computers and Accessibility (New York, NY, USA, Oct. 2018), 15-27.

[17] Boujarwah, F.A., Nazneen, Hong, H., Abowd, G.D. and Arriaga, R.I. 2011. Towards a framework to situate assistive technology design in the context of culture. The proceedings of the 13th international ACM SIGACCESS conference on Computers and accessibility (New York, NY, USA, Oct. 2011), 19-26.

[18] Branham, S. and Harrison, S. 2013. Designing for collocated couples. Connecting Families. Springer. 15-36.

[19] Branham, S.M. and Kane, S.K. 2015. Collaborative Accessibility: How Blind and Sighted Companions Co-Create Accessible Home Spaces. Proceedings of the 33rd Annual ACM Conference on Human Factors in Computing Systems (New York, NY, USA, 2015), 2373-2382.

[20] Branham, S.M. and Kane, S.K. 2015. The Invisible Work of Accessibility: How Blind Employees Manage Accessibility in Mixed-Ability Workplaces. Proceedings of the 17th International ACM SIGACCESS Conference on Computers \& Accessibility (New York, NY, USA, 2015), 163-171.

[21] Branham, S.M. and Mukkath Roy, A.R. 2019. Reading Between the Guidelines: How Commercial Voice Assistant Guidelines Hinder Accessibility for Blind Users. Proceedings of the ACM SIGACCESS Conference on Computers \& Accessibility (ASSETS '19) (Pittsburgh, PA, Oct. 2019).

[22] Braun, V., Clarke, V. and Terry, G. 2014. Thematic analysis. Qual Res Clin Health Psychol. 24, (2014), 95-114.

[23] Brewer, R. and Piper, A.M. 2016. “ Tell It Like It Really Is” A Case of Online Content Creation and Sharing Among Older Adult Bloggers. Proceedings of the 2016 CHI Conference on Human Factors in Computing Systems (2016), 5529-5542.

[24] Brush, A.J.B., Lee, B., Mahajan, R., Agarwal, S., Saroiu, S. and Dixon, C. 2011. Home Automation in the Wild: Challenges and Opportunities. Proceedings of the SIGCHI Conference on Human Factors in Computing Systems (New York, NY, USA, 2011), 2115-2124
[25] Caregiver Statistics: Demographics: https://www.caregiver.org/resource/ caregiver-statistics-demographics/. Accessed: 2021-07-05.

[26] Caroux, L., Consel, C., Dupuy, L. and Sauzéon, H. 2014. Verification of daily activities of older adults: a simple, non-intrusive, low-cost approach. Proceedings of the 16th international ACM SIGACCESS conference on Computers \& accessibility (New York, NY, USA, Oct. 2014), 43-50.

[27] Consel, C., Dupuy, L. and Sauzéon, H. 2015. A Unifying Notification System To Scale Up Assistive Services. Proceedings of the 17th International ACM SIGACCESS Conference on Computers \& Accessibility (New York, NY, USA, Oct. 2015), $77-87$.

[28] Davis, L., Fulginiti, A., Kriegel, L. and Brekke, J.S. 2012. Deinstitutionalization? Where have all the people gone? Current psychiatry reports. 14, 3 (2012), 259-269.

[29] Davis, L.J. 1995. Enforcing normalcy: Disability, deafness, and the body. Verso.

[30] Dawe, M. 2006. Desperately Seeking Simplicity: How Young Adults with Cognitive Disabilities and Their Families Adopt Assistive Technologies. Proceedings of the SIGCHI Conference on Human Factors in Computing Systems (New York, NY, USA, 2006), 1143-1152.

[31] Desjardins, A., Wakkary, R. and Odom, W. 2015. Investigating Genres and Perspectives in HCI Research on the Home. Proceedings of the 33rd Annual ACM Conference on Human Factors in Computing Systems (New York, NY, USA, Apr. 2015), 3073-3082.

[32] Deutsch, A. 1948. The shame of the states. (1948).

[33] van Dijk, B., Dadlani, P., van Halteren, A. and Biemans, M. 2010. Life changes, connection stays: photo sharing and social connectedness for people with special needs. Proceedings of the 28th Annual European Conference on Cognitive Ergonomics (New York, NY, USA, Aug. 2010), 135-142.

[34] Dimitrov, Y., Gospodinova, Z., Wheeler, R., Žnidaršič, M., Ženko, B., Veleva, V. and Miteva, N. 2019. Social activity modelling and multimodal coaching for active aging. Proceedings of the 12th ACM International Conference on PErvasive Technologies Related to Assistive Environments (New York, NY, USA, Jun. 2019), 608-615.

[35] DiSalvo, C., Sengers, P. and Brynjarsdóttir, H. 2010. Mapping the landscape of sustainable HCI. Proceedings of the SIGCHI Conference on Human Factors in Computing Systems (New York, NY, USA, Apr. 2010), 1975-1984.

[36] Doelling, K., Shin, J. and Popa, D.O. 2014. Service robotics for the home: a state of the art review. Proceedings of the 7th International Conference on PErvasive Technologies Related to Assistive Environments (New York, NY, USA, May 2014), $1-8$.

[37] Elor, A., Teodorescu, M. and Kurniawan, S. 2018. Project Star Catcher: A Novel Immersive Virtual Reality Experience for Upper Limb Rehabilitation. ACM Transactions on Accessible Computing. 11, 4 (Nov. 2018), 20:1-20:25. DOI:https: //doi.org/10.1145/3265755.

[38] Ferdous, S., Fegaras, L. and Makedon, F. 2010. Applying data warehousing technique in pervasive assistive environment. Proceedings of the 3 rd International Conference on PErvasive Technologies Related to Assistive Environments (New York, NY, USA, Jun. 2010), 1-7.

[39] Foucault, M. 1970. The archaeology of knowledge. Social Science Information. 9 , 1 (Feb. 1970), 175-185. DOI:https://doi.org/10.1177/053901847000900108.

[40] Frauenberger, C. 2015. Disability and Technology: A Critical Realist Perspective. Proceedings of the 17th International ACM SIGACCESS Conference on Computers \& Accessibility (New York, NY, USA, 2015), 89-96.

[41] Gerben Dejong, M.P.A. 1979. Independent living: From social movement to analytic paradigm. Archives of physical medicine and rehabilitation. 60, 10 (1979), 435-436.

[42] Gerling, K.M., Mandryk, R.L. and Kalyn, M.R. 2013. Wheelchair-based game design for older adults. Proceedings of the 15th International ACM SIGACCESS Conference on Computers and Accessibility (New York, NY, USA, Oct. 2013), 1-8.

[43] Gugenheimer, J., Plaumann, K., Schaub, F., Di Campli San Vito, P., Duck, S., Rabus, M. and Rukzio, E. 2017. The Impact of Assistive Technology on Communication Quality Between Deaf and Hearing Individuals. Proceedings of the 2017 ACM Conference on Computer Supported Cooperative Work and Social Computing (New York, NY, USA, 2017), 669-682.

[44] Hayes, K., Hoagland, G.W., McKearn, M., Fise, P., Workman, M., Weiner, N. and Bayliss, W. 2017. Financing Long-Term Services and Supports: Seeking Bipartisan Solutions in Politically Challenging Times. Bipartisan Policy Center.

[45] Hernandez, H.A., Ketcheson, M., Schneider, A., Ye, Z., Fehlings, D., Switzer, L., Wright, V., Bursick, S.K., Richards, C. and Graham, T.C.N. 2014. Design and evaluation of a networked game to supportsocial connection of youth with cerebral palsy. Proceedings of the 16th international ACM SIGACCESS conference on Computers \& accessibility (New York, NY, USA, Oct. 2014), 161-168.

[46] Hofmann, M., Kasnitz, D., Mankoff, J. and Bennett, C.L. 2020. Living Disability Theory: Reflections on Access, Research, and Design. The 22nd International ACM SIGACCESS Conference on Computers and Accessibility (New York, NY, USA, Oct. 2020), 1-13.

[47] Holbø, K., Bøthun, S. and Dahl, Y. 2013. Safe walking technology for people with dementia: what do they want? Proceedings of the 15th International ACM SIGACCESS Conference on Computers and Accessibility (New York, NY, USA, Oct. 2013), 1-8. 
[48] Hornof, A., Whitman, H., Sutherland, M., Gerendasy, S. and McGrenere, J. 2017. Designing for the "Universe of One": Personalized Interactive Media Systems for People with the Severe Cognitive Impairment Associated with Rett Syndrome. Proceedings of the 2017 CHI Conference on Human Factors in Computing Systems (New York, NY, USA, May 2017), 2137-2148.

[49] Jain, D., Lin, A., Guttman, R., Amalachandran, M., Zeng, A., Findlater, L. and Froehlich, J. 2019. Exploring Sound Awareness in the Home for People who are Deaf or Hard of Hearing. Proceedings of the 2019 CHI Conference on Human Factors in Computing Systems (New York, NY, USA, May 2019), 1-13.

[50] Johnson, H.M. 2003. The disability gulag. The New York Times Magazine. 23 (2003).

[51] Judge, T.K., Neustaedter, C., Harrison, S. and Blose, A. 2011. Family Portals: Connecting Families Through a Multifamily Media Space. Proceedings of the SIGCHI Conference on Human Factors in Computing Systems (New York, NY, USA, 2011), 1205-1214.

[52] Judge, T.K., Neustaedter, C. and Kurtz, A.F. 2010. The Family Window: The Design and Evaluation of a Domestic Media Space. Proceedings of the SIGCHI Conference on Human Factors in Computing Systems (New York, NY, USA, 2010), 2361-2370.

[53] Kannabiran, G., Bardzell, J. and Bardzell, S. 2011. How HCI Talks About Sexuality: Discursive Strategies, Blind Spots, and Opportunities for Future Research Proceedings of the SIGCHI Conference on Human Factors in Computing Systems (New York, NY, USA, 2011), 695-704.

[54] Khan, K.S., Kunz, R., Kleijnen, J. and Antes, G. 2003. Five Steps to Conducting a Systematic Review. Journal of the Royal Society of Medicine. 96, 3 (Mar. 2003), 118-121. DOI:https://doi.org/10.1177/014107680309600304.

[55] Kidd, C.D., Orr, R., Abowd, G.D., Atkeson, C.G., Essa, I.A., MacIntyre, B., Mynatt E., Starner, T.E. and Newstetter, W. 1999. The Aware Home: A Living Laboratory for Ubiquitous Computing Research. Cooperative Buildings. Integrating Information, Organizations, and Architecture (1999), 191-198.

[56] Korn, O., Bieber, G. and Fron, C. 2018. Perspectives on Social Robots: From the Historic Background to an Experts' View on Future Developments. Proceedings of the 11th PErvasive Technologies Related to Assistive Environments Conference (New York, NY, USA, Jun. 2018), 186-193.

[57] Korn, O. and Tietz, S. 2017. Strategies for Playful Design when Gamifying Rehabilitation: A Study on User Experience. Proceedings of the 10th Internationa Conference on PErvasive Technologies Related to Assistive Environments (New York, NY, USA, Jun. 2017), 209-214.

[58] Kosch, T., Wennrich, K., Topp, D., Muntzinger, M. and Schmidt, A. 2019. The digital cooking coach: using visual and auditory in-situ instructions to assist cognitively impaired during cooking. Proceedings of the 12th ACM International Conference on PErvasive Technologies Related to Assistive Environments (New York, NY, USA, Jun. 2019), 156-163.

[59] Kosch, T., Woźniak, P.W., Brady, E. and Schmidt, A. 2018. Smart Kitchens for People with Cognitive Impairments: A Qualitative Study of Design Requirements. Proceedings of the 2018 CHI Conference on Human Factors in Computing Systems. Association for Computing Machinery. 1-12.

[60] Laws, M. 2020. Why we capitalize 'Black' (and not 'white'). Columbia fournalism Review. (Jun. 2020)

[61] Lazar, A., Edasis, C. and Piper, A.M. 2017. A Critical Lens on Dementia and Design in HCI. CHI (2017), 2175-2188.

[62] Learning Disabilities Association of Ameria Disability and Criminal Justice Reform.

[63] Liu, G., Ding, X., Yu, C., Gao, L., Chi, X. and Shi, Y. 2019. "I Bought This for Me to Look More Ordinary": A Study of Blind People Doing Online Shopping. Proceedings of the 2019 CHI Conference on Human Factors in Computing Systems (New York, NY, USA, May 2019), 1-11.

[64] Liu, P., Ding, X. and Gu, N. 2016. "Helping Others Makes Me Happy": Social Interaction and Integration of People with Disabilities. Proceedings of the 19th ACM Conference on Computer-Supported Cooperative Work \& Social Computing (New York, NY, USA, 2016), 1596-1608.

[65] Lopez, J.P., Martín, D., Moreno, F., Hernández-Peñaloza, G., Álvarez, F., Marín, M., Carrasco, L. and Burgos, M. 2018. Acceptance of Cognitive Games through Smart TV Applications in Patients with Parkinson's Disease. Proceedings of the 11th PErvasive Technologies Related to Assistive Environments Conference (New York, NY, USA, Jun. 2018), 428-433.

[66] Madjaroff, G. and Mentis, H. 2017. Narratives of Older Adults with Mild Cognitive Impairment and Their Caregivers. Proceedings of the 19th International ACM SIGACCESS Conference on Computers and Accessibility (New York, NY, USA, 2017), 140-149.

[67] Mankoff, J., Hayes, G.R. and Kasnitz, D. 2010. Disability studies as a source of critical inquiry for the field of assistive technology. Proceedings of the 12th international ACM SIGACCESS conference on Computers and accessibility (2010), $3-10$.

[68] Mazmanian, M. and Lanette, S. 2017. "Okay, One More Episode": An Ethnography of Parenting in the Digital Age. Proceedings of the 2017 ACM Conference on Computer Supported Cooperative Work and Social Computing (New York, NY, USA, 2017), 2273-2286.
[69] McGee-Lennon, M.R., Wolters, M.K. and Brewster, S. 2011. User-centred multimodal reminders for assistive living. Proceedings of the SIGCHI Conference on Human Factors in Computing Systems (New York, NY, USA, May 2011), 21052114

[70] McNeill, A., Briggs, P., Pywell, J. and Coventry, L. 2017. Functional privacy concerns of older adults about pervasive health-monitoring systems. Proceedings of the 10th International Conference on PErvasive Technologies Related to Assistive Environments (New York, NY, USA, Jun. 2017), 96-102.

[71] Meliones, A. and Kokkovos, S. 2015. Privacy-preserving intelligent networked video surveillance for patient monitoring and alarm detection. Proceedings of the 8th ACM International Conference on PErvasive Technologies Related to Assistive Environments (New York, NY, USA, Jul. 2015), 1-8.

[72] Mentis, H.M., Madjaroff, G. and Massey, A.K. 2019. Upside and Downside Risk in Online Security for Older Adults with Mild Cognitive Impairment. Proceedings of the 2019 CHI Conference on Human Factors in Computing Systems (New York, NY, USA, May 2019), 1-13.

[73] Mulvenna, M., Martin, S., Sävenstedt, S., Bengtsson, J., Meiland, F., Dröes, R.M., Hettinga, M., Moelaert, F. and Craig, D. 2010. Designing \& evaluating a cognitive prosthetic for people with mild dementia. Proceedings of the 28th Annual European Conference on Cognitive Ergonomics (New York, NY, USA, Aug. 2010), $11-18$.

[74] Neves, B.B., Franz, R.L., Munteanu, C., Baecker, R. and Ngo, M. 2015. "My Hand Doesn't Listen to Me!": Adoption and Evaluation of a Communication Technology for the 'Oldest Old.' Proceedings of the 33rd Annual ACM Conference on Human Factors in Computing Systems (New York, NY, USA, Apr. 2015), 15931602.

[75] Nguyễn, A.T. and Pendleton, M. 2020. Recognizing Race in Language: Why We Capitalize "Black" and "White." Center for the Study of Social Policy. (Mar. 2020).

[76] Noll, S. 2018. Institutions for People with Disabilities in North America. The Oxford Handbook of Disability History. (2018), 307.

[77] Nursing homes site of $40 \%$ of US COVID-19 deaths: 2020. https: //www.cidrap.umn.edu/news-perspective/2020/06/nursing-homes-site40-us-covid-19-deaths. Accessed: 2020-09-14.

[78] Oliver, M. 2013. The social model of disability: Thirty years on. Disability \& society. 28, 7 (2013), 1024-1026.

[79] Olmstead Decision: https://www.olmsteadrights.org/about-olmstead/. Accessed: 2020-09-13.

[80] Parnandi, A., Karappa, V., Son, Y., Shahin, M., McKechnie, J., Ballard, K., Ahmed, B. and Gutierrez-Osuna, R. 2013. Architecture of an automated therapy tool for childhood apraxia of speech. Proceedings of the 15th International ACM SIGACCESS Conference on Computers and Accessibility (New York, NY, USA, Oct. 2013), 1-8.

[81] Peirce's Notion of Abduction: 1958. https://www.pdcnet.org/pdc/bvdb.nsf/ purchase?openform\&fp=jphil\&id=jphil_1958_0055_0014_0593_0597. Accessed: 2020-09-13.

[82] Peters, C., Hermann, T., Wachsmuth, S. and Hoey, J. 2014. Automatic Task Assistance for People with Cognitive Disabilities in Brushing Teeth - A User Study with the TEBRA System. ACM Transactions on Accessible Computing. 5, 4 (Mar. 2014), 10:1-10:34. DOI:https://doi.org/10.1145/2579700.

[83] Petrie, H. and Darzentas, J. 2017. Older people and robotic technologies in the home: perspectives from recent research literature. Proceedings of the 10th International Conference on PErvasive Technologies Related to Assistive Environments (New York, NY, USA, Jun. 2017), 29-36.

[84] Pew Research Demographics of Mobile Device Ownership and Adoption in the United States. Pew Research Center: Internet, Science \& Tech.

[85] Pradhan, A., Mehta, K. and Findlater, L. 2018. "Accessibility Came by Accident": Use of Voice-Controlled Intelligent Personal Assistants by People with Disabilities. Proceedings of the 2018 CHI Conference on Human Factors in Computing Systems (New York, NY, USA, 2018), 459:1-459:13.

[86] Profita, H., Albaghli, R., Findlater, L., Jaeger, P. and Kane, S.K. 2016. The AT Effect: How Disability Affects the Perceived Social Acceptability of Head-Mounted Display Use. Proceedings of the 2016 CHI Conference on Human Factors in Computing Systems (New York, NY, USA, 2016), 4884-4895.

[87] Profita, H.P., Stangl, A., Matuszewska, L., Sky, S., Kushalnagar, R. and Kane, S.K. 2018. "Wear It Loud" How and Why Hearing Aid and Cochlear Implant Users Customize Their Devices. ACM Transactions on Accessible Computing (TACCESS). 11, 3 (2018), 1-32.

[88] Ringland, K.E., Nicholas, J., Kornfield, R., Lattie, E.G., Mohr, D.C. and Reddy, M. 2019. Understanding mental ill-health as psychosocial disability: Implications for assistive technology. The 21st International ACM SIGACCESS Conference on Computers and Accessibility (2019), 156-170.

[89] Rode, J.A. 2010. The Roles That Make the Domestic Work. Proceedings of the 2010 ACM Conference on Computer Supported Cooperative Work (New York, NY, USA, 2010), 381-390.

[90] Scheffler, T., Schindler, S., Lewerenz, M. and Schnor, B. 2011. A privacy-aware localization service for healthcare environments. Proceedings of the 4th International Conference on PErvasive Technologies Related to Assistive Environments (New York, NY, USA, May 2011), 1-8. 
[91] Schildbach, S. and Schildbach, C. 2018. Criminalization through transinstitutionalization: a critical review of the Penrose hypothesis in the context of compensation imprisonment. Frontiers in psychiatry. 9, (2018), 534.

[92] Schlesinger, A., Edwards, W.K. and Grinter, R.E. 2017. Intersectional HCI: En gaging Identity through Gender, Race, and Class. Proceedings of the $2017 \mathrm{CH}$ Conference on Human Factors in Computing Systems (New York, NY, USA, May 2017), 5412-5427.

[93] Schön, D.A. 2017. The reflective practitioner: How professionals think in action. Routledge.

[94] Sharma, S., Achary, K., Kaur, H., Linna, J., Turunen, M., Varkey, B., Hakulinen, J. and Daeeyya, S. 2018. 'Wow! You're Wearing a Fitbit, You're a Young Boy Now!": Socio-Technical Aspirations for Children with Autism in India. Proceedings of the 20th International ACM SIGACCESS Conference on Computers and Accessibility (New York, NY, USA, Oct. 2018), 174-184.

[95] She, P. and Stapleton, D. 2006. A Review of Disability Data for the Institutional Population: Research Brief. Employment and Disability Institute Collection. (Jan. 2006).

[96] Shinn, M., Gottlieb, J., Wett, J.L., Bahl, A., Cohen, A. and Baron Ellis, D. 2007. Predictors of homelessness among older adults in New York city: disability, economic, human and social capital and stressful events. fournal of Health Psychology. 12, 5 (Sep. 2007), 696-708. DOI:https://doi.org/10.1177/1359105307080581.

[97] Shinohara, K., Bennett, C.L., Pratt, W. and Wobbrock, J.O. 2018. Tenets for social accessibility: Towards humanizing disabled people in design. ACM Transactions on Accessible Computing (TACCESS). 11, 1 (2018), 1-31.

[98] Shinohara, K. and Wobbrock, J.O. 2011. In the Shadow of Misperception: Assistive Technology Use and Social Interactions. Proceedings of the SIGCHI Conference on Human Factors in Computing Systems (New York, NY, USA, 2011), $705-714$.

[99] Shinohara, K. and Wobbrock, J.O. 2016. Self-Conscious or Self-Confident? A Diary Study Conceptualizing the Social Accessibility of Assistive Technology. ACM Trans. Access. Comput. 8, 2 (Jan. 2016), 5:1-5:31. DOI:https://doi.org/10. $1145 / 2827857$.

[100] Sitbon, L., Brown, R. and Fell, L. 2019. Turning Heads: Designing Engaging Immersive Video Experiences to Support People with Intellectual Disability when Learning Everyday Living Skills. The 21st International ACM SIGACCESS Conference on Computers and Accessibility (New York, NY, USA, Oct. 2019), 171-182.

[101] Skorupska, K., Nunez, M., Kopec, W. and Nielek, R. 2018. Older Adults and Crowdsourcing: Android TV App for Evaluating TEDx Subtitle Quality. Proceedings of the ACM on Human-Computer Interaction. 2, CSCW (Nov. 2018), 159:1-159:23. DOI:https://doi.org/10.1145/3274428.

[102] Spiel, K., Frauenberger, C., Keyes, O. and Fitzpatrick, G. 2019. Agency of Autistic Children in Technology Research-A Critical Literature Review. ACM Transactions on Computer-Human Interaction. 26, 6 (Nov. 2019), 38:1-38:40. DOI:https://doi.org/10.1145/3344919.
[103] Sterling, T.D., Lichstein, M., Scarpino, F. and Stuebing, D. 1964. Professional Computer Work for the Blind. Commun. ACM. 7, 4 (Apr. 1964), 228-230. DOI:https://doi.org/10.1145/364005.364054.

[104] Storer, K.M. and Branham, S.M. 2019. "That's the Way Sighted People Do It": What Blind Parents Can Teach Technology Designers About Co-Reading with Children. Proceedings of the 2019 on Designing Interactive Systems Conference (2019), 385-398

[105] Storer, K.M., Judge, T.K. and Branham, S.M. 2020. "All in the Same Boat:" Tradeoffs of Voice Assistant Ownership for Mixed-Visual-Ability Families. Proceedings of the 2020 ACM SIGCHI Conference on Human Factors in Computing Systems (Honolulu, HI, Apr. 2020).

[106] Thayer, A., Bietz, M.J., Derthick, K. and Lee, C.P. 2012. I Love You, Let's Share Calendars: Calendar Sharing As Relationship Work. Proceedings of the ACM 2012 Conference on Computer Supported Cooperative Work (New York, NY, USA, 2012), 749-758.

[107] Thieme, A., Bennett, C.L., Morrison, C., Cutrell, E. and Taylor, A.S. 2018. "I Can Do Everything but See!" - How People with Vision Impairments Negotiate Their Abilities in Social Contexts. Proceedings of the 2018 CHI Conference on Human Factors in Computing Systems (New York, NY, USA, 2018), 203:1-203:14.

[108] Vacher, M., Aman, F., Rossato, S., Portet, F. and Lecouteux, B. 2019. Making Emergency Calls More Accessible to Older Adults Through a Hands-free Speech Interface in the House. ACM Transactions on Accessible Computing. 12, 2 (Jun. 2019), 8:1-8:25. DOI:https://doi.org/10.1145/3310132.

[109] Vacher, M., Caffiau, S., Portet, F., Meillon, B., Roux, C., Elias, E., Lecouteux, B. and Chahuara, P. 2015. Evaluation of a Context-Aware Voice Interface for Ambient Assisted Living: Qualitative User Study vs. Quantitative System Evaluation. ACM Transactions on Accessible Computing. 7, 2 (May 2015), 5:1-5:36. DOI:https: //doi.org/10.1145/2738047.

[110] Vines, J., Pritchard, G., Wright, P., Olivier, P. and Brittain, K. 2015. An Age-Old Problem: Examining the Discourses of Ageing in HCI and Strategies for Future Research. ACM Transactions on Computer-Human Interaction. 22, 1 (Feb. 2015), 2:1-2:27. DOI:https://doi.org/10.1145/2696867.

[111] Viswanathan, P., Little, J.J., Mackworth, A.K. and Mihailidis, A. 2011. Navigation and obstacle avoidance help (NOAH) for older adults with cognitive impairment: a pilot study. The proceedings of the 13th international ACM SIGACCESS conference on Computers and accessibility (New York, NY, USA, Oct. 2011), 43-50.

[112] Wang, E.Q. and Piper, A.M. 2018. Accessibility in Action: Co-Located Collaboration Among Deaf and Hearing Professionals. Proc. ACM Hum.-Comput. Interact. 2, CSCW (Nov. 2018), 180:1-180:25. DOI:https://doi.org/10.1145/3274449.

[113] Wodak, R. and Meyer, M. 2009. Critical discourse analysis: History, agenda, theory and methodology. Methods of critical discourse analysis. 1-33.

[114] Wodak, R. and Meyer, M. 2015. Methods of Critical Discourse Studies. SAGE.

[115] Yuan, C.W., Hanrahan, B.V., Lee, S., Rosson, M.B. and Carroll, J.M. 2017. I Didn't Know That You Knew I Knew: Collaborative Shopping Practices Between People with Visual Impairment and People with Vision. Proc. ACM Hum.-Comput. Interact. 1, CSCW (Dec. 2017), 118:1-118:18. DOI:https://doi.org/10.1145/3134753. 